\title{
Looking Again at the Diagnosis of Brucellosis Difficulties in Iran
}

\author{
Massoud Hajia ${ }^{1}$, Faramarz Masjedian Jazi ${ }^{2}$ \\ 1. Department of Molecular Biology, Research Center of Health Reference Laboratory, Ministry of Health and Medical Education, \\ Tehran, Iran \\ 2. Department of Microbiology, School of Medicine, Iran University of Medical Science, Tehran, Iran
}

\section{Article Information}

\section{Article history:}

Received: 2018/06/11

Accepted: 2018/06/30

Available online: 2018/06/30

\section{Article Subject:}

Clinical Microbiology

IJMM 2018; 12(2):68-77

Corresponding author:

Faramarz Masjedian Jazi Asistant Professor of Medical

Microbiology, Department of

Microbiology, School of

Medicine, Iran University of

Medical Science, Tehran, Iran

Tel: 021-88058649

Email:

fmasjedian@yahoo.com

Use your device to scan and read the article online

\section{Abstract}

Based on the frequently reports, final diagnosis of brucellosis is facing delay problem. Significant percentage of hospitalized patients has been under unspecified and mostly single treatment. Therefore laboratory evidence and use of highly sensitive methods have an important role in final diagnosis.

The increasing of brucellosis in recent years is due to increasing livestock infections and insufficient coverage of vaccination; we should also consider absence of active supervision on the distribution of livestock products specifically in local manufacturers and inefficient diagnostic procedures. Lack of coordination between responsible and decision-making centers such as subsidiaries of Ministry of Health and Agriculture has an important role. Unfortunately, despite the publication of numerous scientific papers, especially in the field of epidemiology, no clear picture of the status of brucellosis has been presented by the responsible authorities in Iran.

In this study, we tried to look at the situation of brucellosis in Iran and to find out more about the limitations and advantages of each method by describing the diagnostic properties of each method. The aim of this study is to provide routine diagnosis limitations and errors to undertake necessary revision in diagnostic measures, in particular at the health labs level.

Keywords: Brucellosis, Epidemiology, Laboratory Diagnosis

How to cite this article:

Hajia M, Masjedian Jazi F. Looking Again at the Diagnosis of Brucellosis Difficulties in Iran. Iran J Med Microbiol. 2018; 12 (2) : 68-77 


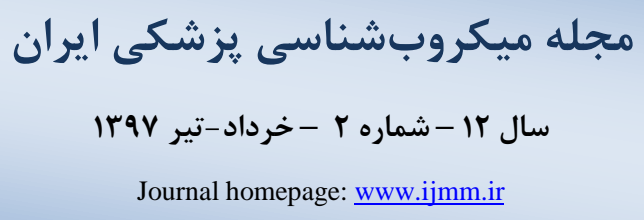

\section{نكاهى مجدد به مشكلات تشخيصى بروسلوزيس در ايران

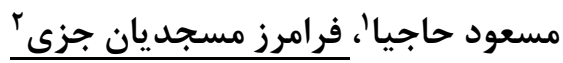

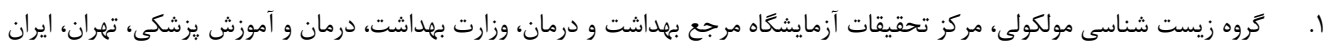

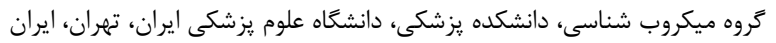

\section{جكيده}

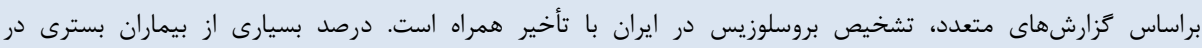

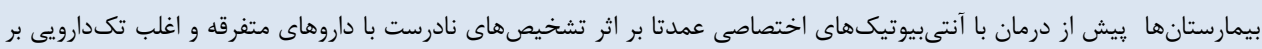

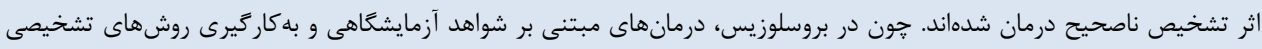

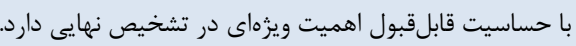

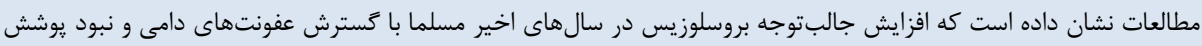

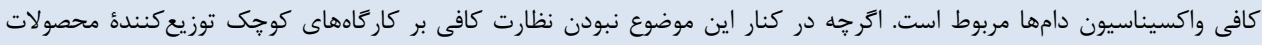

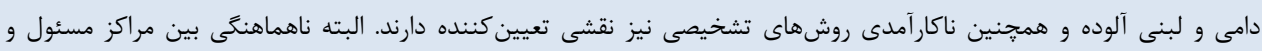

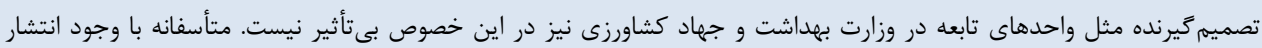

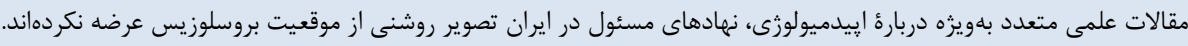

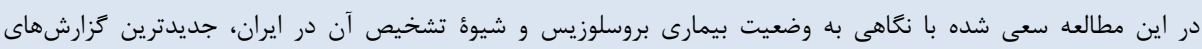

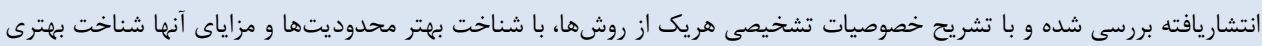

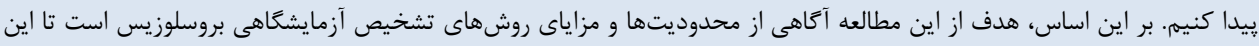

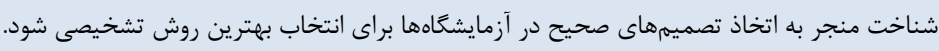
كلمات كليدى: بروسلوزيس، إيدميولوزى، تشخيص آزمايشخاهى، مزايا، محدوديتها

كبىرايت (): حق جاب، نشر و استفاده علمى از اين مقاله براى مجله ميكروبشناسى بزشكى ايران محفوظ است.
اطلاعات مقاله - اله

تاريخجِه مقاله

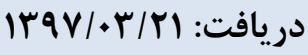

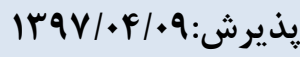

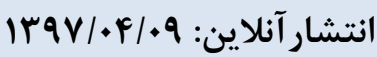

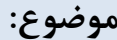

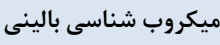

IJMM1397;12(2): 68-77

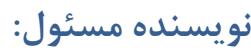

فرامرز مسجديان جزى

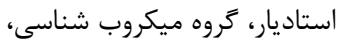

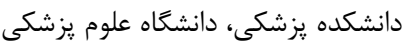

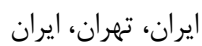

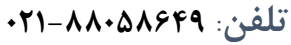

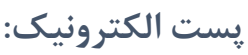

fmasjedian@yahoo.com

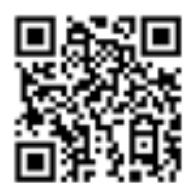

مقل مه

كونهها در مناطق آندميك، همجنين نبود بررسىهاى دقيق متمركز نسبت به ميزان حساسيت روشهاى تشخيصى سبب شده است كه

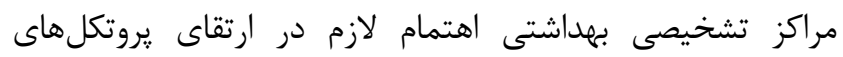

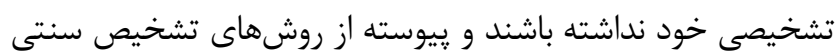

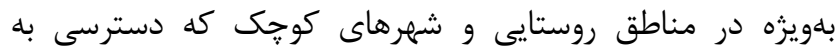

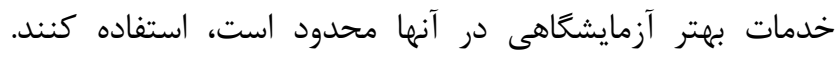

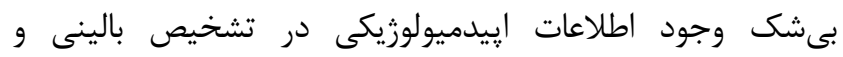
آزمايشخاهى بيمارى نقش مهمى دارد. همجنين نداشتن آكاهى

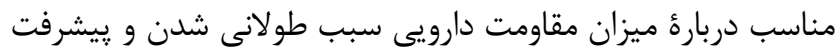

بين بيمارىهاى عفونى, بروسلوزيس يكى از شايعترين بيمارىهاى زئونوز بوده كه محدود به انسان نيست. در انتشار اين بين

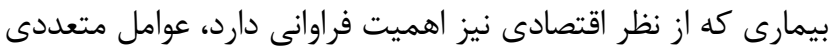
از جمله نبودن يوشش مناسب واكسيناسيون دامها دركير هستند. بىترديد تردد آزاد دامها در مناطق مرزى نقش بالايى در درئ نبود

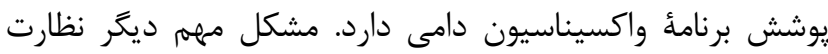

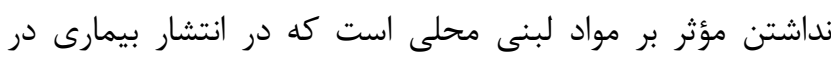

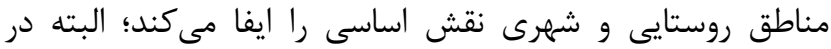

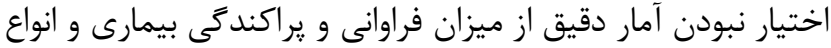


كه در يك مزرعه، در صورت وجود بيمارى با هريك از گونهها تمامى جهاريايان در معرض خطر ابتلا به بيمارى هستند. براساس ززارشهاى متعدد، راه غالب انتقال بروسلا به انسان بـان انتقال از راه گَوارشى با مصرف محصولات لبنى غيرياستوريزه مثل شير تازه و يا ساير محصولات تهيهشده از شير غيرياستوريزه است؛

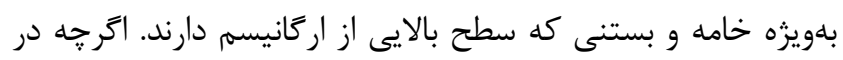
برخى از موارد انتقال از طريق تماسهاى مستقيم با احشاء دام آلوده در مناطق داميرورى، كشتاركاهها و ساير مشاغلى كه با دام سروكار

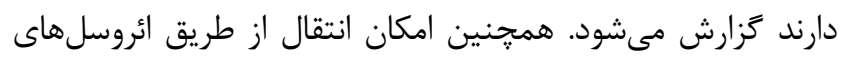

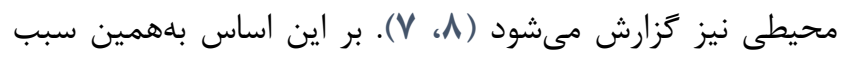
اين بيمارى در مناطق روستايى نسبت به مناطق شهرى فراوانى

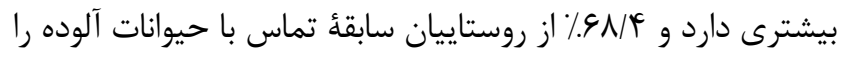
دارند. بيمارى در مناطق روستايى در مقايسه با مناطق شهرى

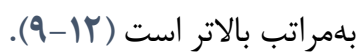
بسيارى از كشورها اعلام كردهاند كه قادر به ريشهكن كردن بيمارى هستند؛ اما متأسفانه بيمارى بروسلوزيس در بسيارى از از

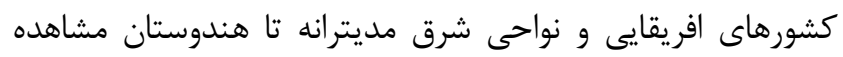
مىشود (ه). شيوع بيمارى نيز از كشورى به كشور ديخر متفاوت

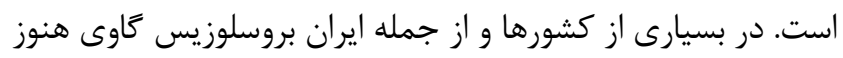

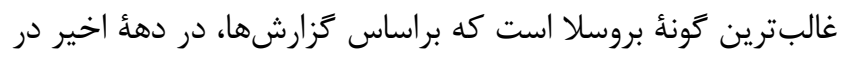
استانهاى شمال شرقى و شمال غربى ايران شيوع وسيعى داشته است. ززارشهاى مربوط به بررسى فراوانى بيمارى در ايران بسيار

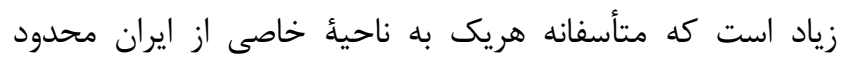

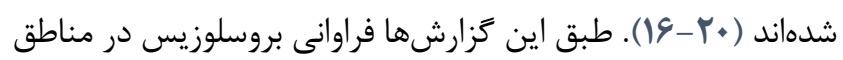
كوناكون، متفاوت بوده و از تنوع بسيارى برخوردار است. بنا بر

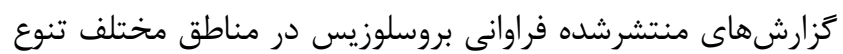

$$
\text { بسيارى دارد. }
$$

بر اين اساس Golshani و Buozari مناطق ايران را از نظر ميزان آلودكى به \& دسته تقسيم كردهاند (F). بررسى جامعتر ديخرى نيز انجام شده است كه Pakzad و همكاران ميزان بروسلوزيس را براساس نمونهها ثبتشده در ايران در اصلة

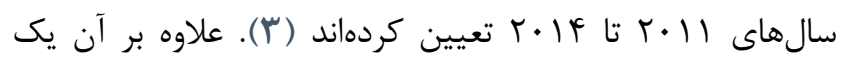

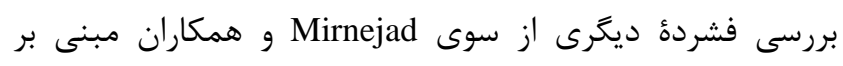
گزارشهاى انتشاريافته انجام شده است كه تا حدودى با كزارش

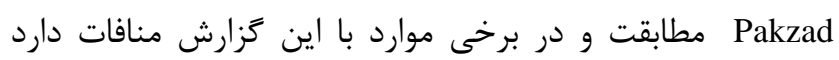
(آا،Y). وقوع كلى در بررسى Pakzad و همكاران براى ايران

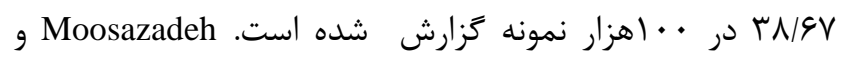

بيمارى و در بسيارى از موارد منجر به عود بروسلوزيس مىشود (1). كنترل بيمارى در اين وضعيت، به هماهنگى سازمان هاى مختلف كه به هريك بانوعى در افزايش آن سهيم هستند، نياز دارد.

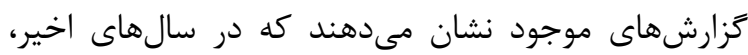
حداقل در برخى از مناطق كشور ما، ميزان بروسلوزيس افزايش موحون

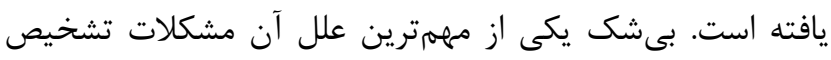

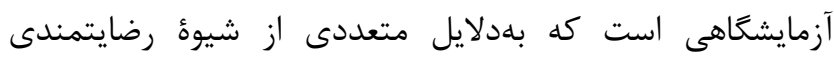
برخوردار نيست. وجود موارد منفى كاذب در روش كشت وردئ

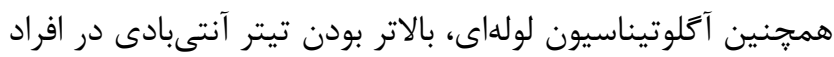

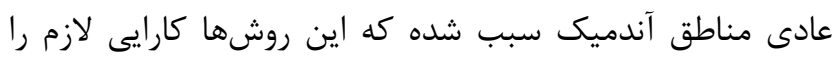

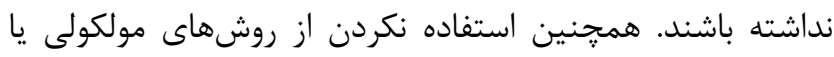
حتى ساير روشهاى تشخيصى در بسيارى از آزمايشگاههاى مراكز بهداشتى بر بيجيدگى هایى تشخيصى اين بيمارى افزوده

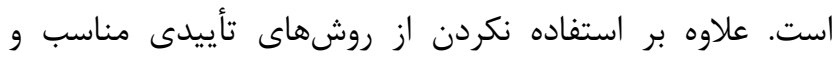
جايگزين، مىتوان به عوامل محدودكننده تشخيصى مثل رايين بودن كيفيت كيتهاى موجود در بازار و نبود مطالعه جامع

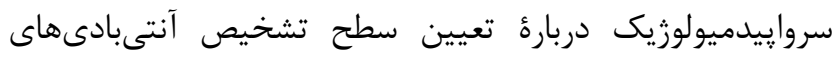
اختصاصى در روشهاى سرولوزيكى نيز اشاره كرد (ه-ب).

\section{برخى نكات مرتبط با إييدميولوزى بروسلوزيس در}

ايران

بروسلوزيس يك بيمارى زئونوز است كه مخزن آن دامهايى هستند كه در زنجيره غذايى انسان نقشى اصلى دارند. اگرجهه ساير جهاريايان نيز ممكن است آلوده شوند ولى نقش آنها مىتواند فقط در انتقال بيمارى بين دامها يا به انسان باشد. مدتى است كه

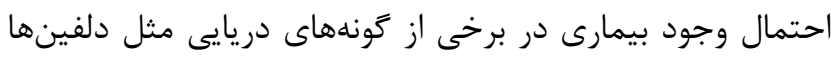
نيز مطرح شده است كه در حال حاضر بدليل عدم وجود ززارش و دسترسى به ميزبان آن، از اين نظر نترانى جدى وجود ندارد (و). بين گونههاى بروسلا بيمارىزايى ناشى از بروسلا سوئيس در ايران

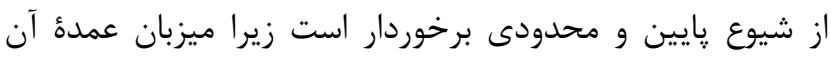

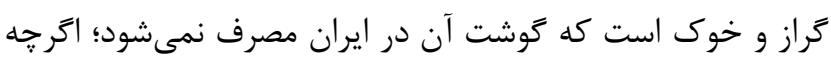
ززارشهاى يراكنده ناشى از آن بلويزه در نواحى شمالى وجود

شدت بيمارى بروسلوزيس به ميزان در معرض بودن و نوع

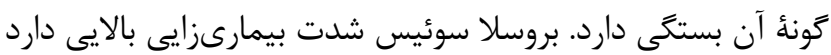

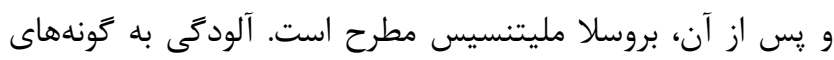

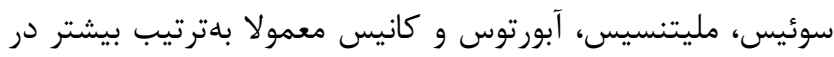

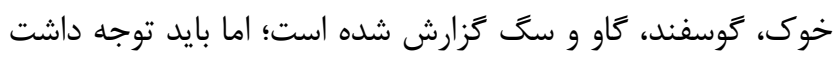


كاذب مىشود، مىتواند درباره ويزگىهاى بيمارى و طبيعت

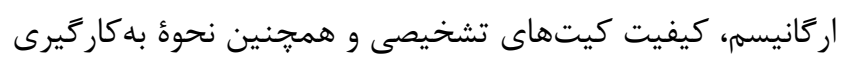

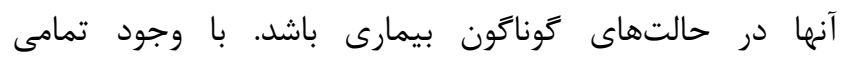

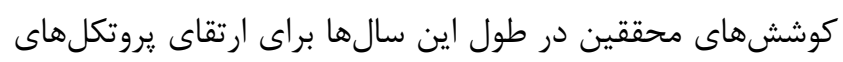

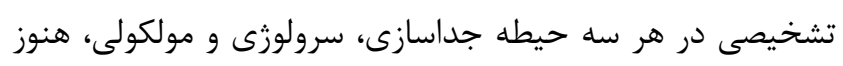

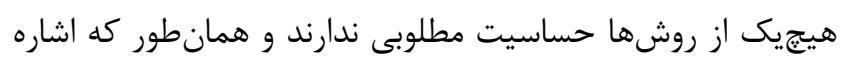

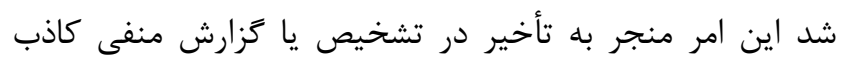

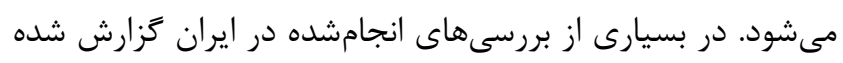

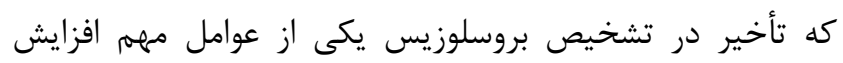

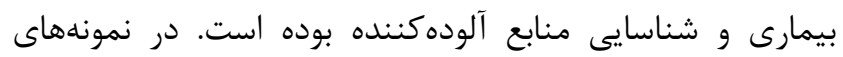

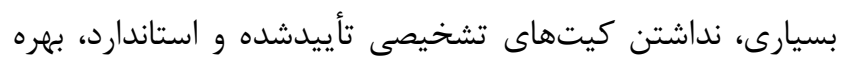

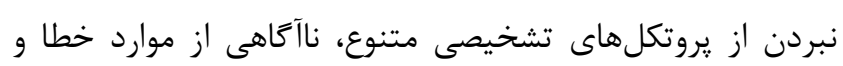

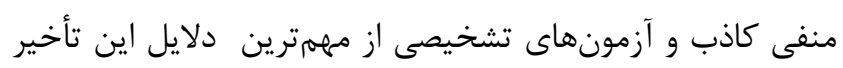

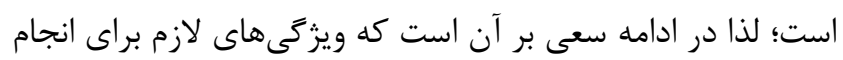

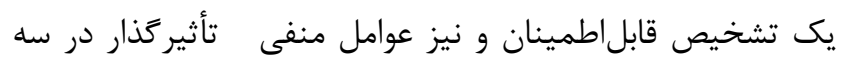

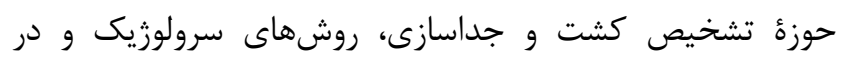
نهايت تشخيص مولكولى بررسى شود.

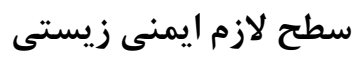

در ابتدا مهمترين موضوعى كه بايد به آنس آن توجه كرد،

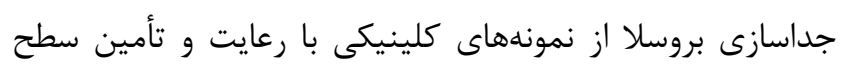

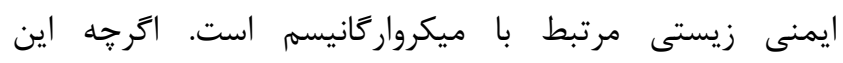

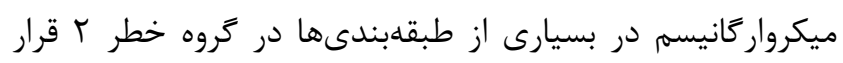

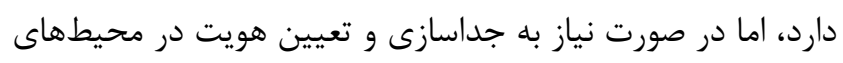

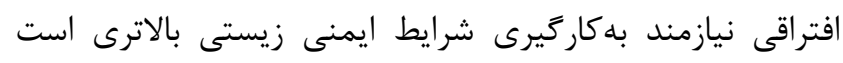

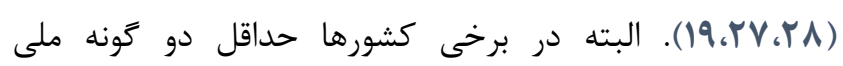

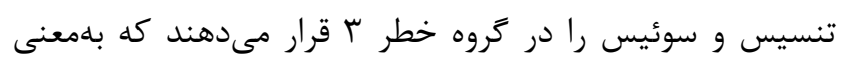

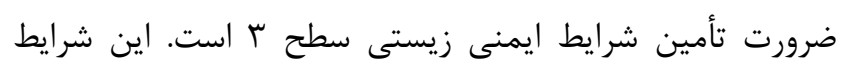

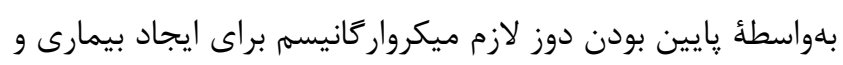

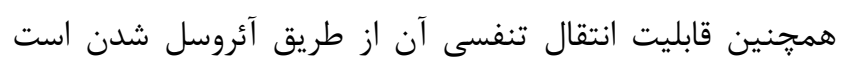

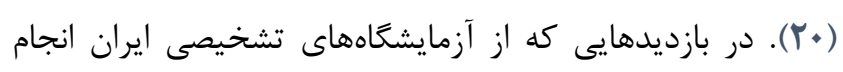

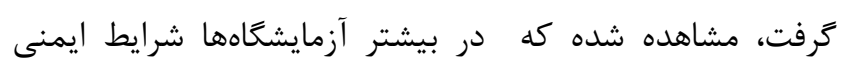

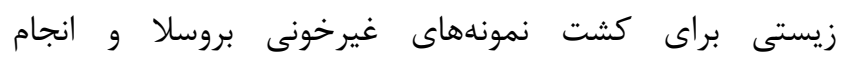

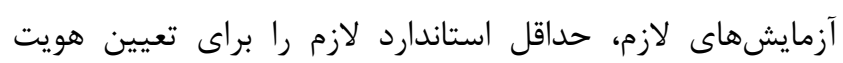

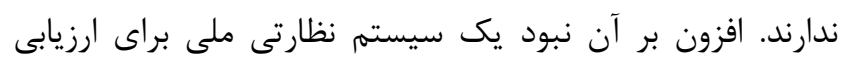

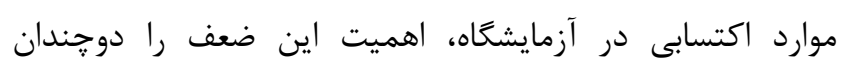

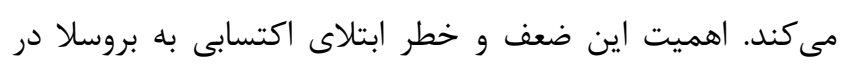

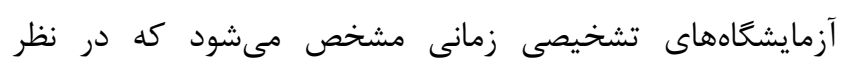

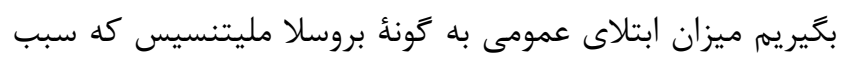

همكاران نيز براساس كزارشهاى منتشرشده، نزديك به همين

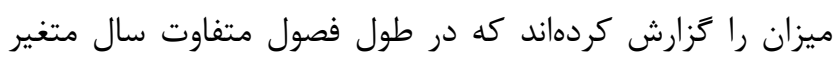

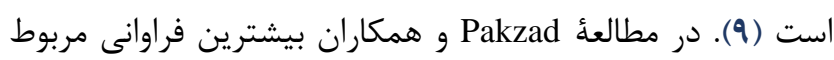

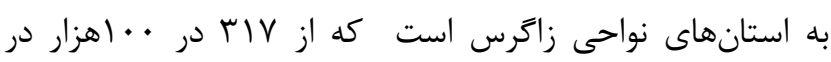

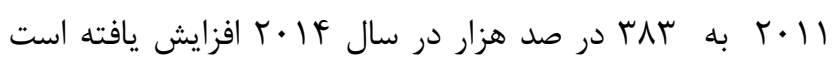

متأسفانه بهدلايل متعدد، آمارى كه نشاندهنده ميزان

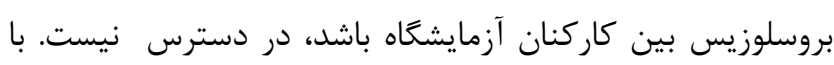

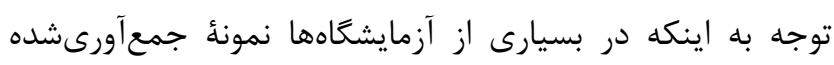

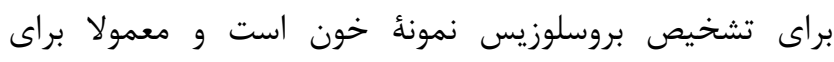
جداسازى و شناسايى فقط به كشت در محيط دى دفازيك اكتفا شده و بواسطه عدم وجود سطح ايمنى زيستى مورد نياز از انجام

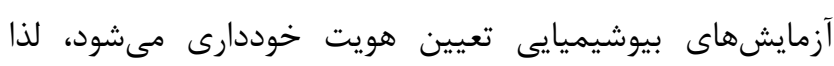

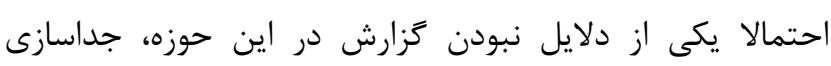

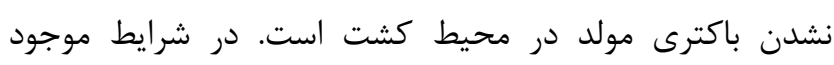

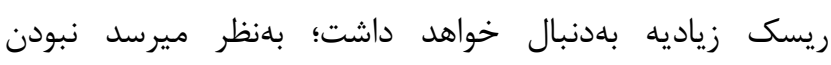

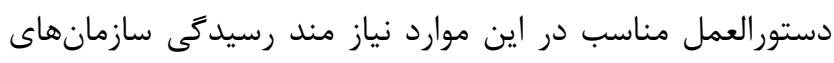
مسئول ميباشد. بايد يادآور شويم كه انتشار سالانهُ بيمارى به تفكيك مناطق

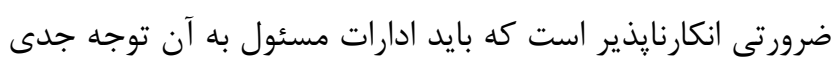

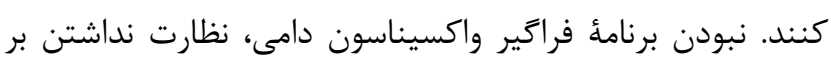

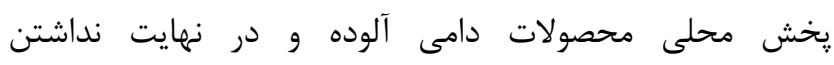

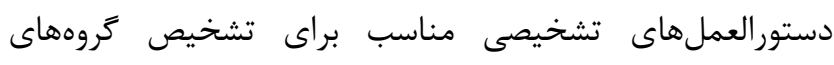
متفاوت بيماران همه سبب شده كه كماكان اين بيمارى دري در ايران

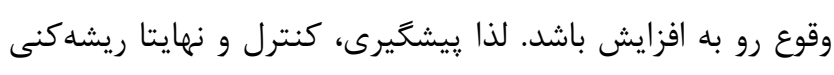

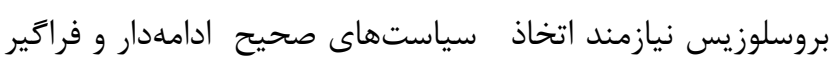

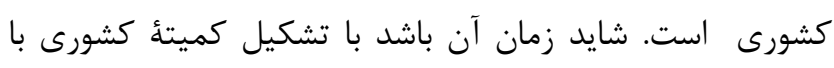

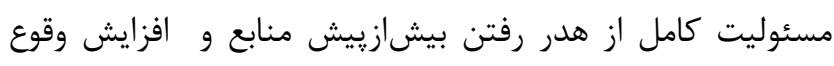
بيمارى جلو گيرى شود.

\section{تشخيص آزمايشغاهيى}

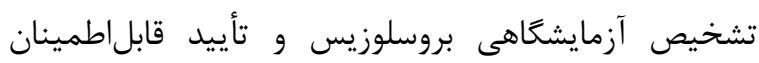

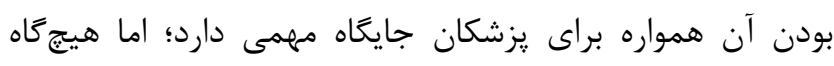

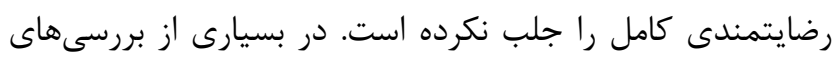

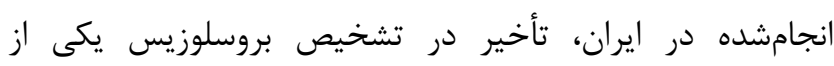

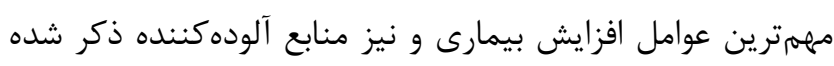

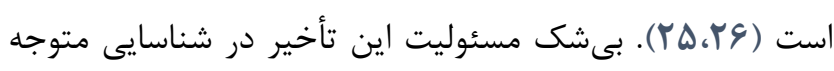

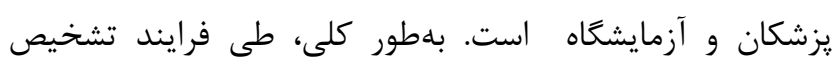

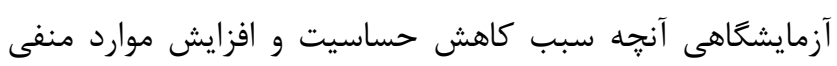


نتايج رضايتبخشترى دارد، بلكه ززارش شده است رشد

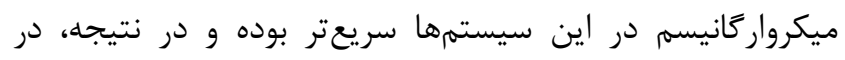

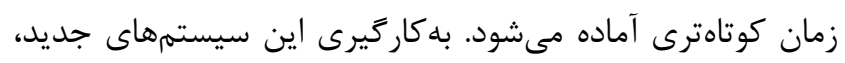

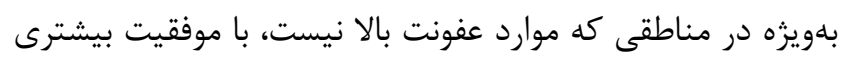

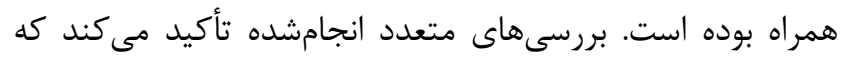

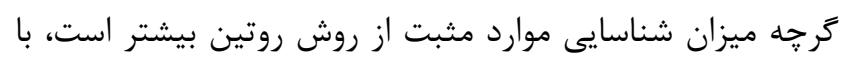

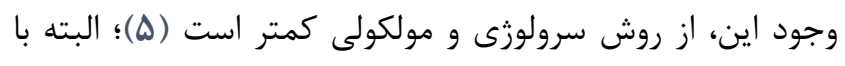

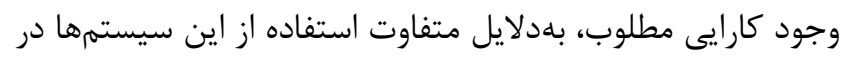

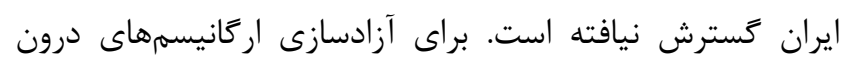

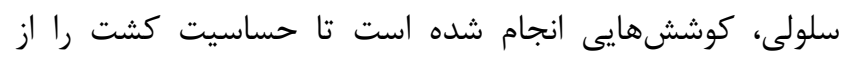

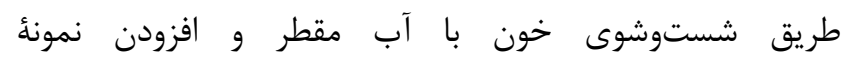

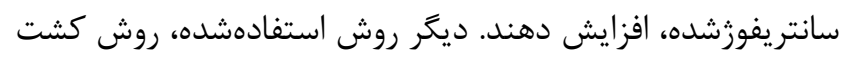

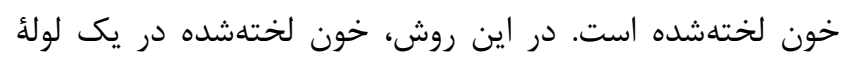

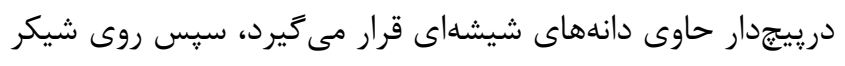

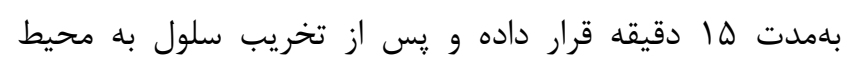

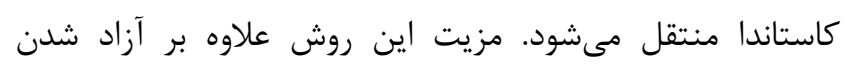

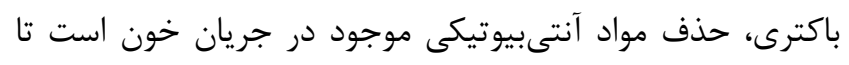

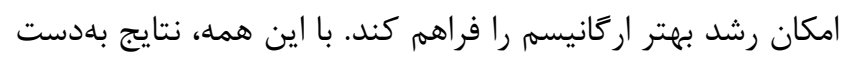

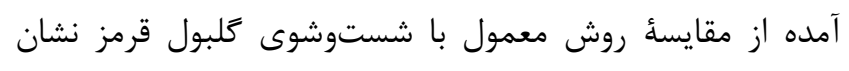

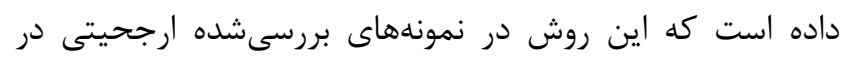

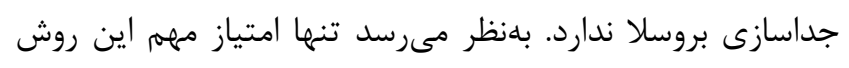
سرعت جداسازى باكترى باشد؛ البته در كنار اين مزيت بايد توجها

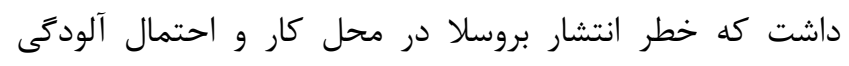

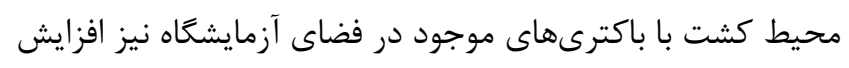

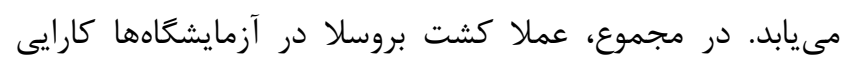

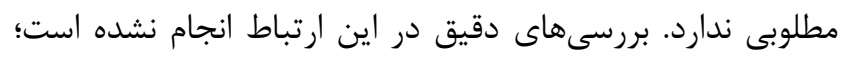

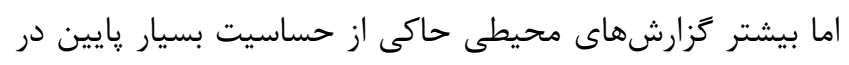

حد ب درصد در ايران هستند (1).

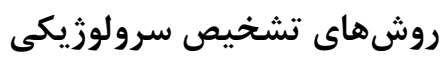

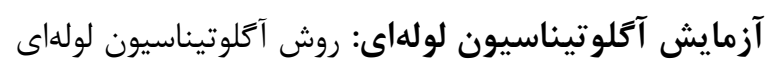

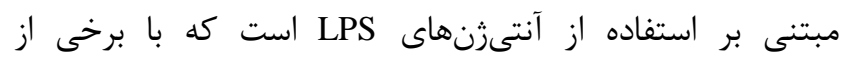

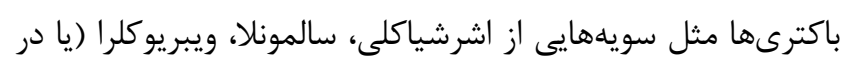

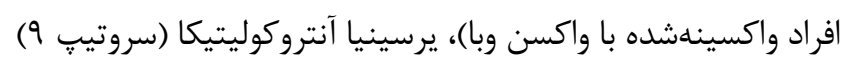

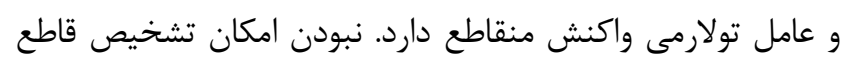

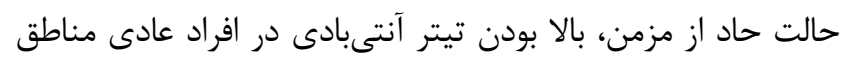

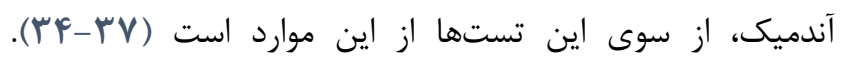

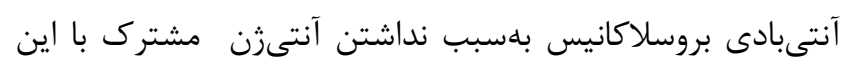

ايجاد فرم حاد بيمارى مىشود نسبت به گونههاى ديخر شيوع

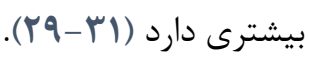

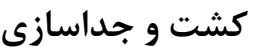

در ايران درصد بالايى از نمونههاى ارسالى به آزمايشعاه

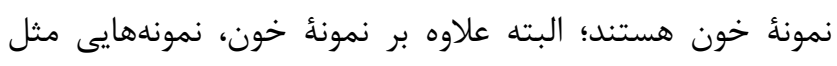

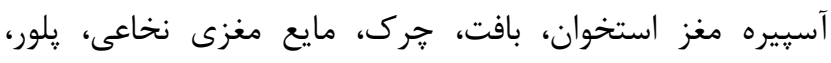

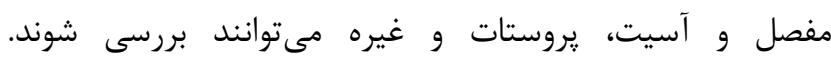

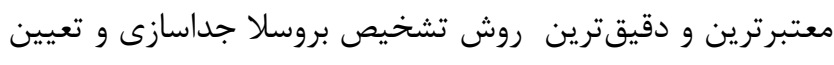

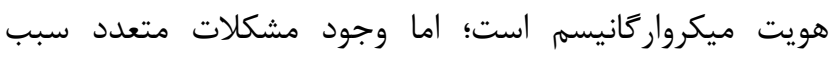

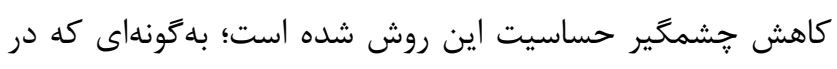

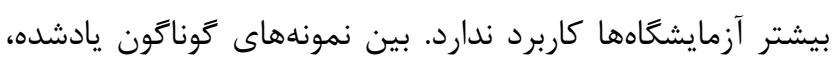

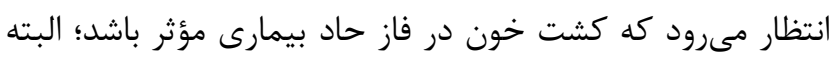

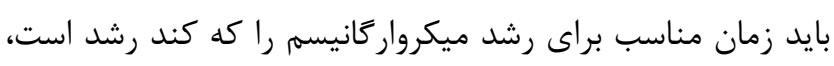
در نظر كرفت. تشخيص احتمالى براساس مورفولوزى، خصوصيات

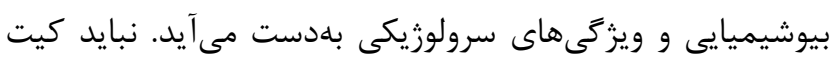

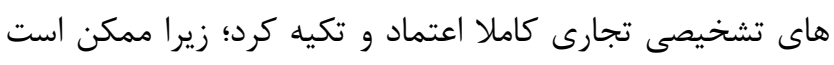

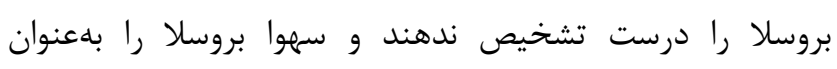

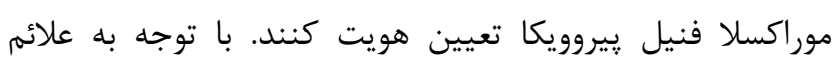

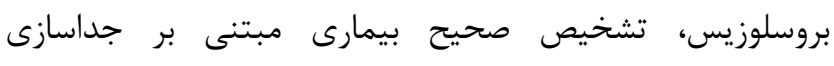

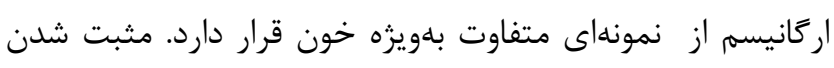

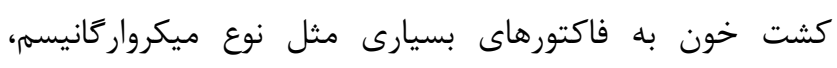

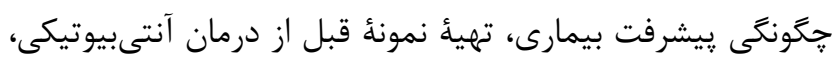

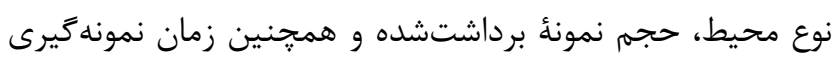

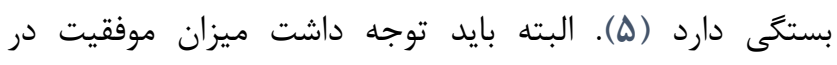

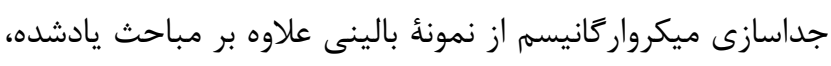

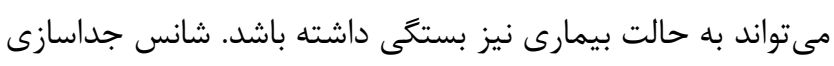

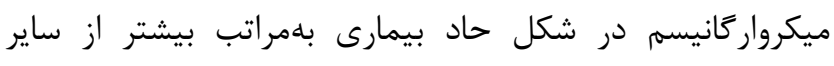

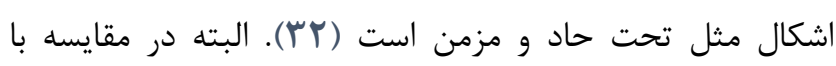

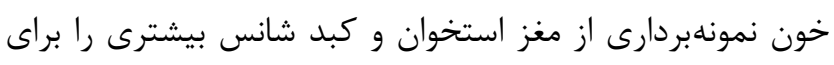

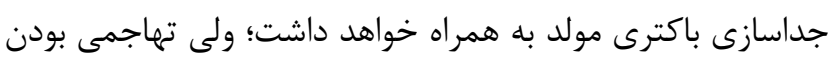

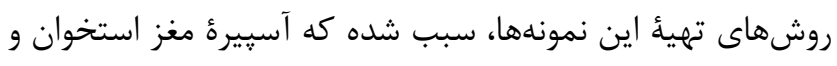

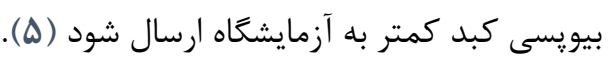

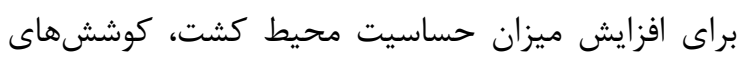

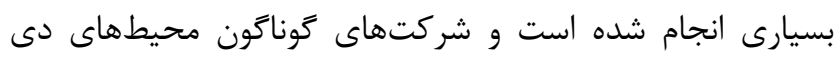

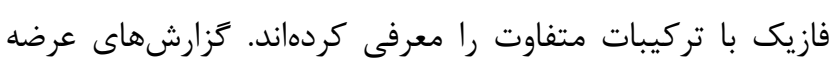

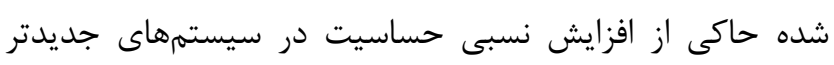

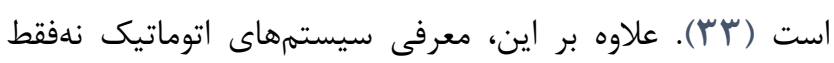




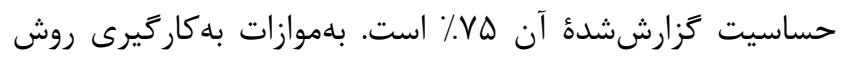

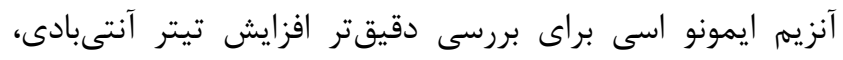

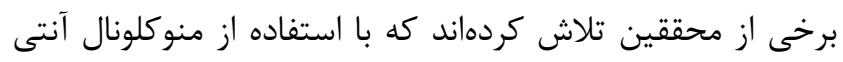

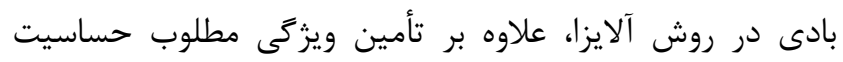

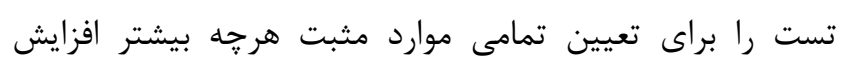

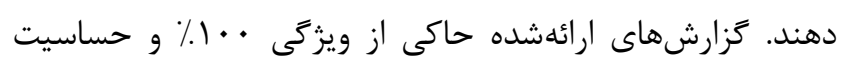

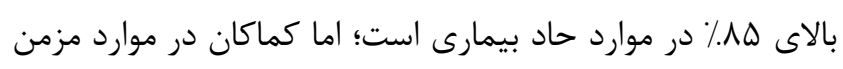

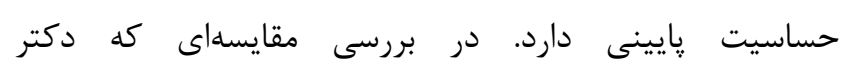
Amirzargar

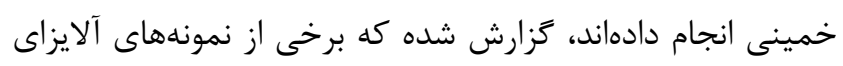

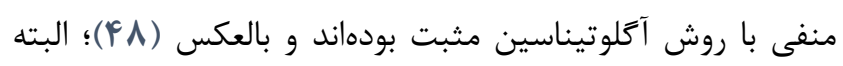

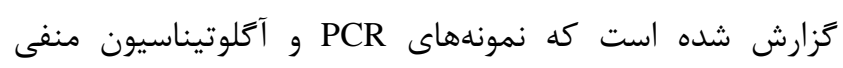

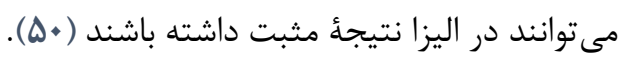
ساير روشهاى تشخيصى: براى تشخيص مننزيت بروسلايى

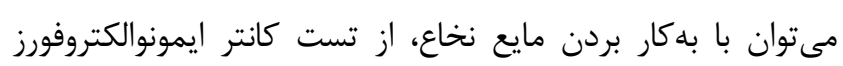

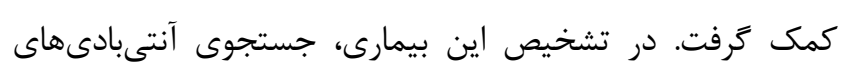

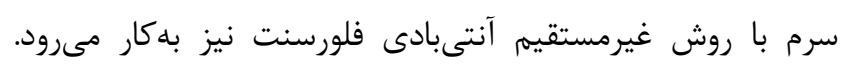

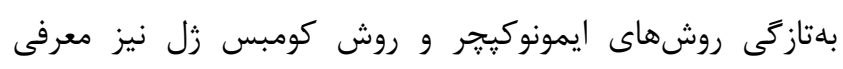

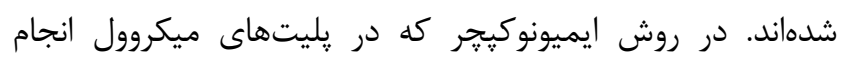

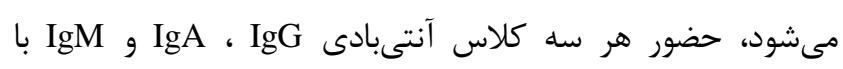

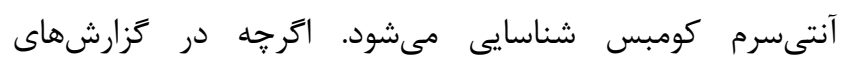
منتشرشده، اين روش حساسيت بيشترى دارد؛ اما ميزان حساسيت

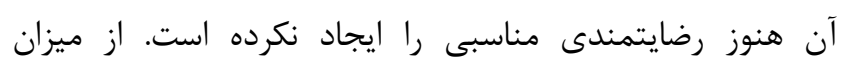
حساسيت روش كومبس زل كه اخيرا فقط در برخى آزمايشكاهـا

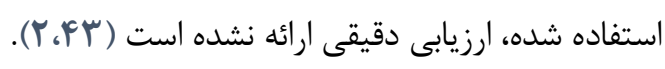

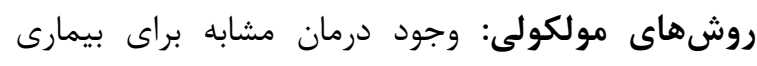

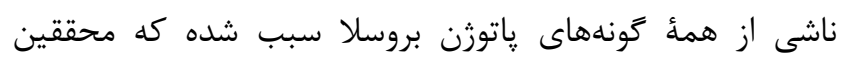

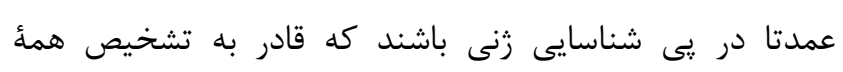

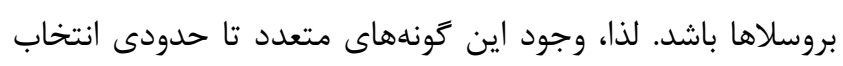
زن مناسب براى انجام كارهاى تشخيص مولكولى را مشكل كاند ساخته

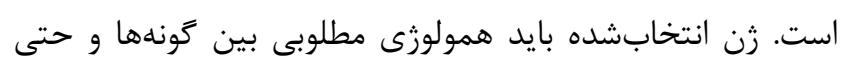

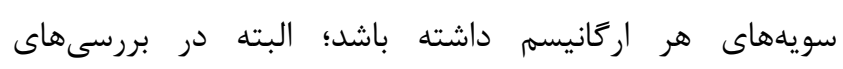

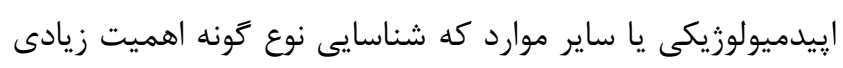

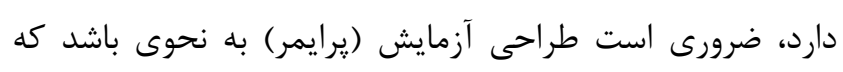

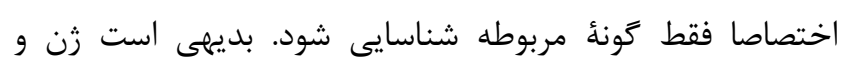

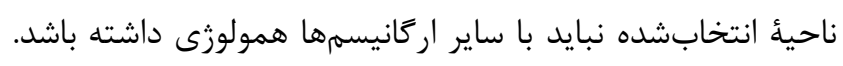

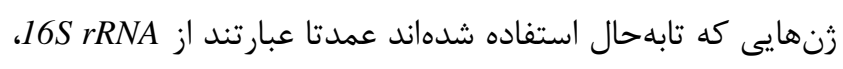

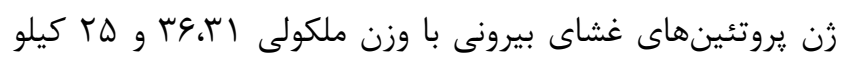

آنتىزن قابلتشخيص نيست. علاوه بر اين، برخى نمونههايى كه در

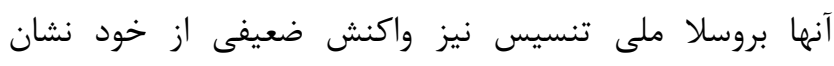

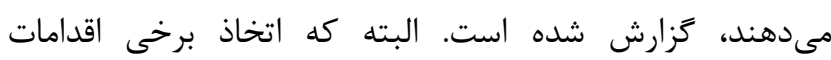

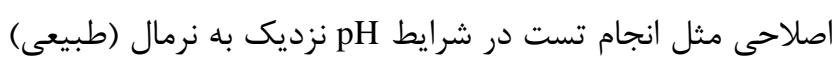

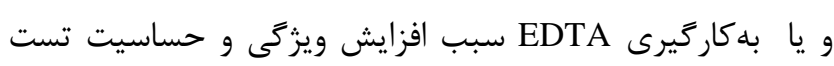

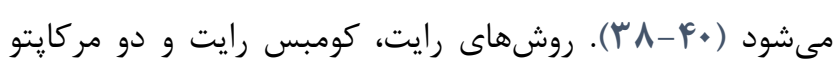

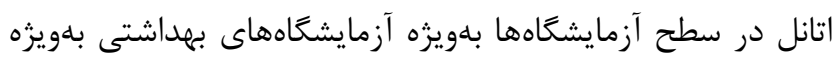

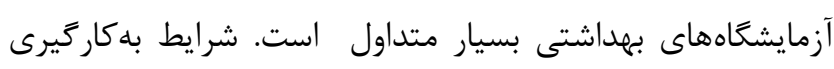

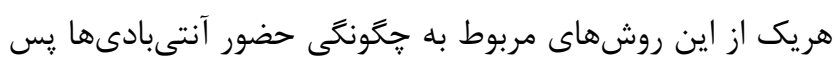
از تحريك سيستم ايمنى و همجنين تظاهرات بالينى بيمار كاريى رايى

خاص خود را دارند (ه). درباره تيتر تشخيصى كه بلهمعنى وجود بيمارن (هارى باشد،

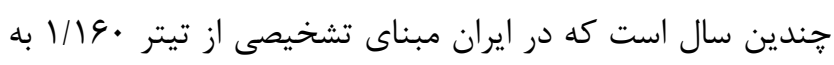

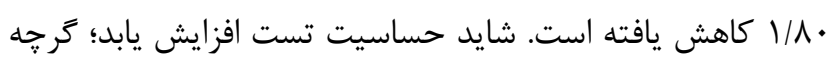

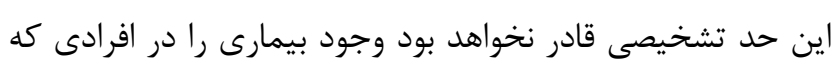

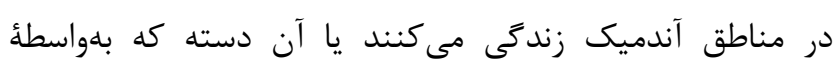

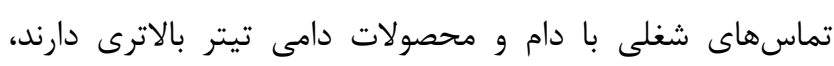

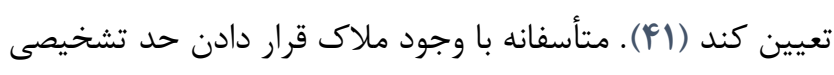

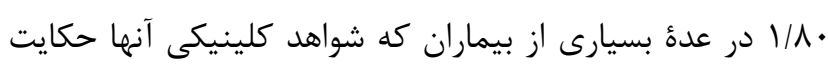

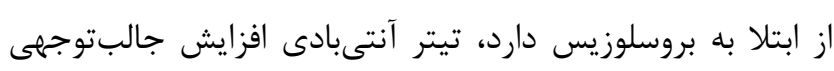

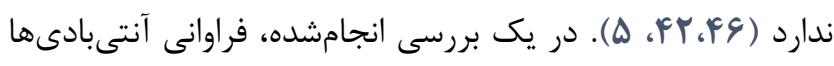
در تستهاى رايت، كومبس و

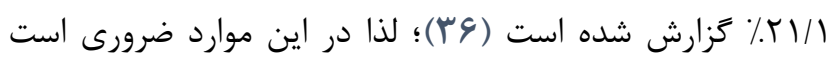
كه از ساير روشهاى تشخيصى آلترناتيو استفاده شود.

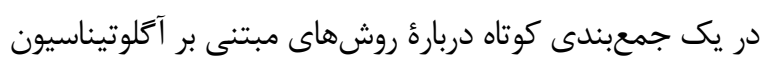

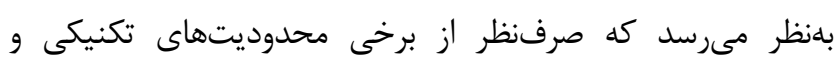

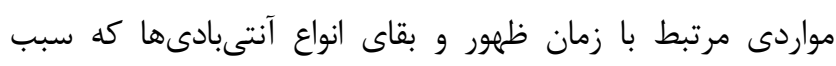

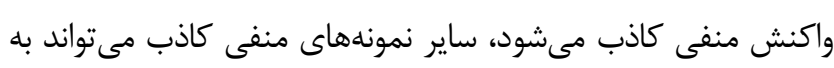

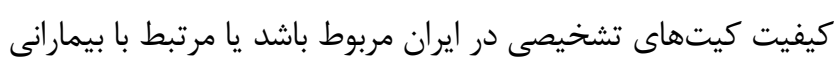

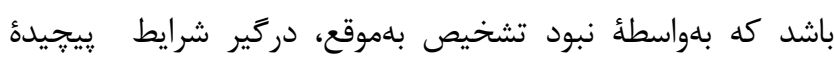

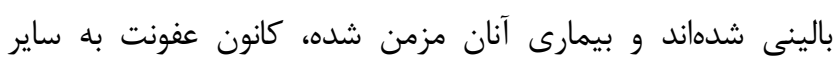
بافتها انتشار يافته باشد.

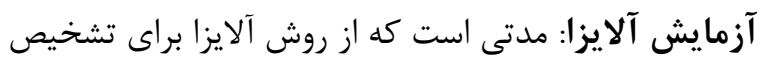

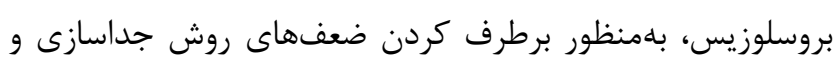

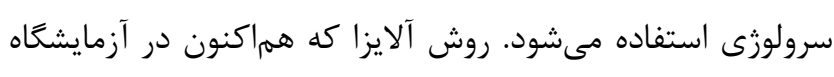

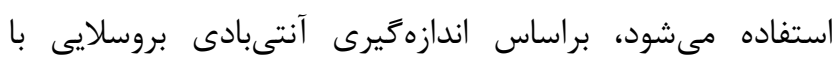

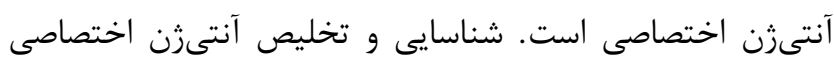
براى فائق آمدن بر مشكل واكنش متقاطع است و و داراى كه 
- استفاده از روش تشخيصى استاندارد: اصولا هيجيك از

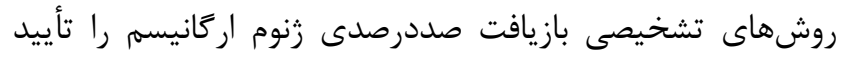

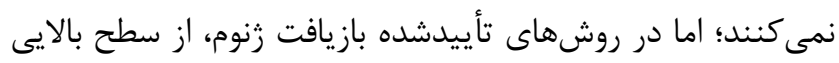

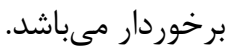

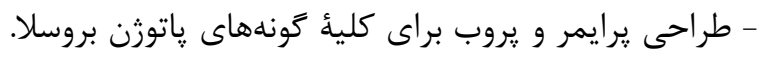

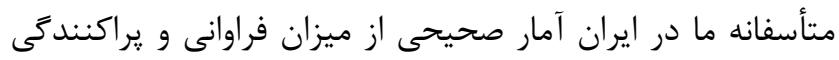

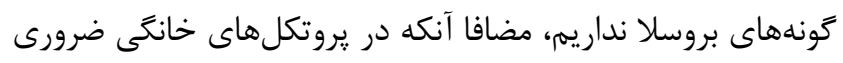

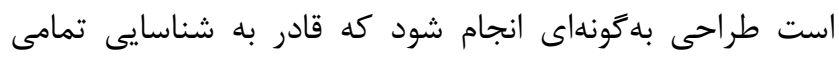

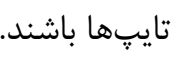

\section{نتيجه}

متأسفانه تشخيص بروسلوزيس در ايران با خالشهاى

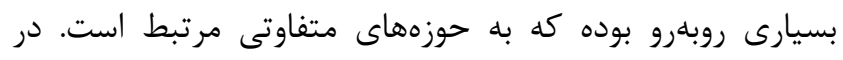

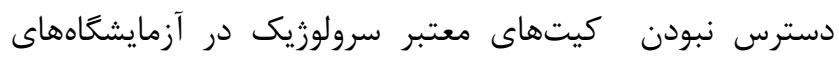

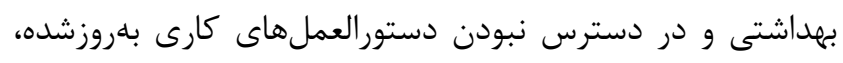

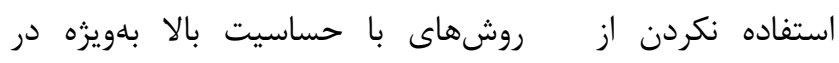

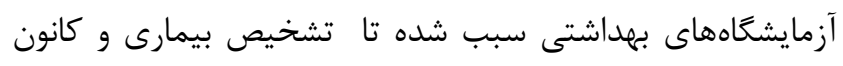

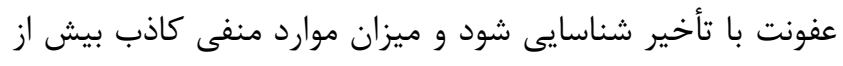

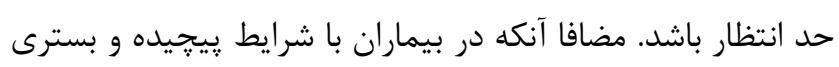

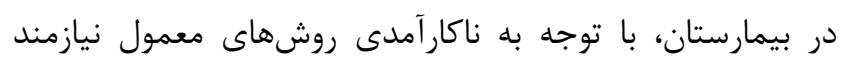

$$
\text { ساير روشهاى تشخيصى مناسبتر هستيم. }
$$

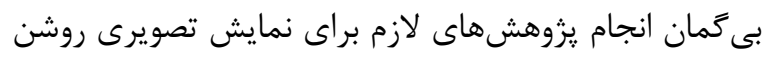

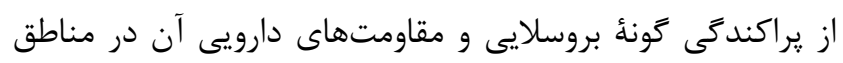

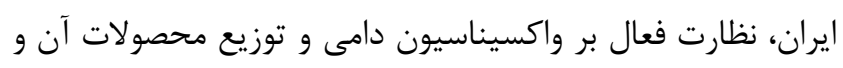

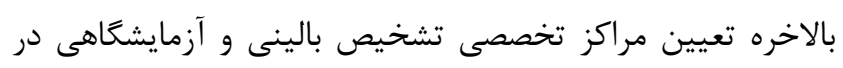

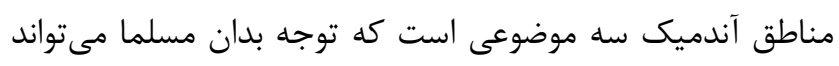

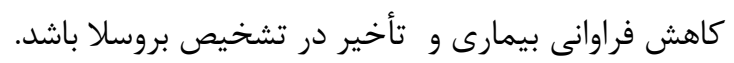

\section{سياسگَزارى}

اين مقاله به درخواست اقاى دكتر ايراجيان تدوين شده

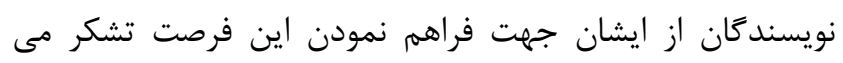
نمايند و اميدواريم براى مخاطبين سودمند قرار كيرد.

$$
\text { تعارض منافع }
$$

بين نويسندًان تعارض در منافع گزارش نشده است.

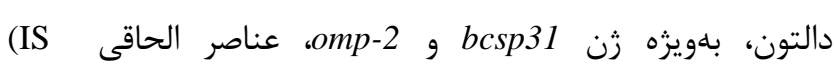
gelements)

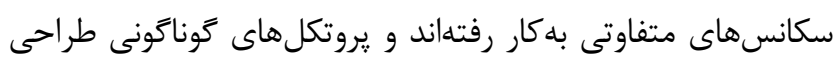

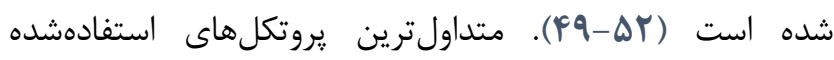

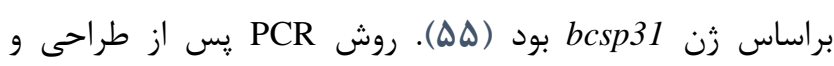

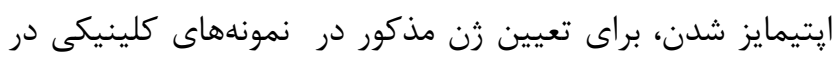

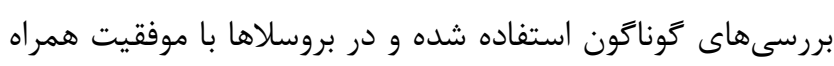

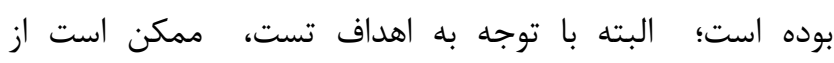

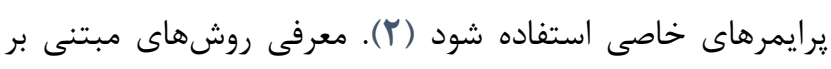

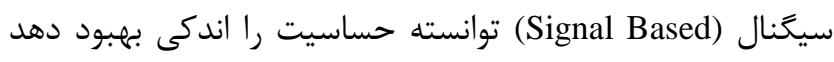

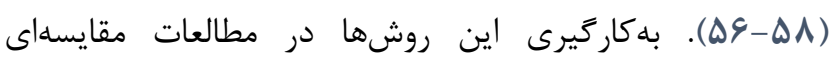

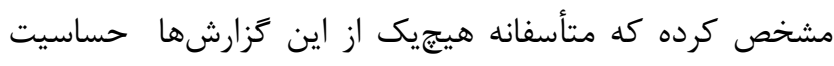

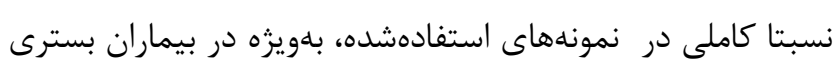

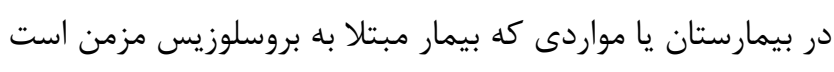
را تأييد نكردهاند (\&V-QV)

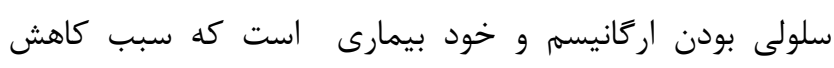

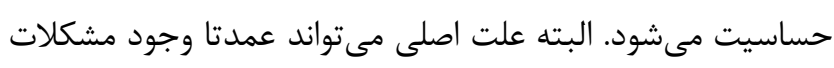

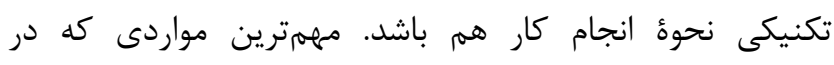

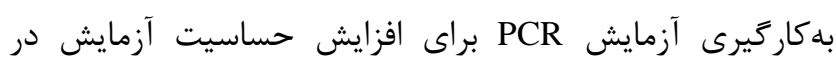

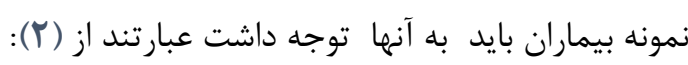

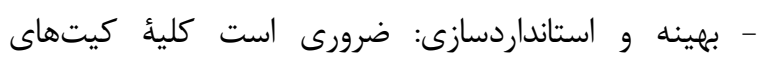
تشخيصى بهويزه روشهاى خانكى، در صورت استفاده از نظر ميزان

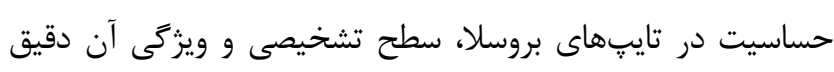

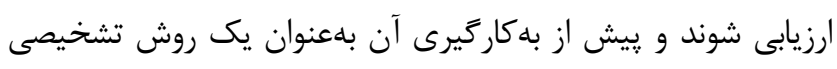
در ارزيابى بالينى بررسى شده باشند.

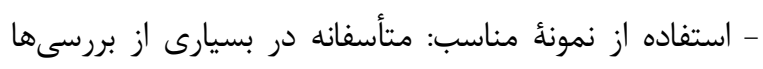

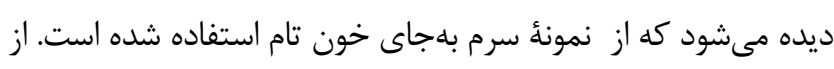

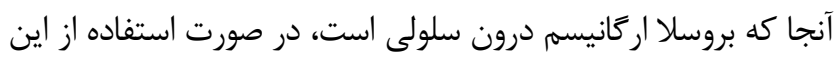
نمونه آن تعداد بروسلا كه درون سلول وجود داريس درون ارند با با اين نمونه از

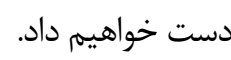

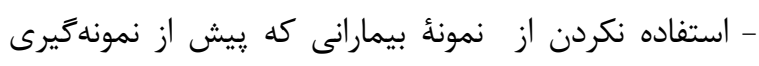

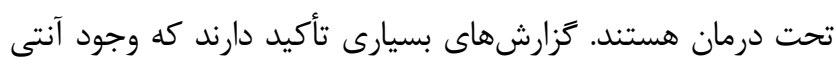

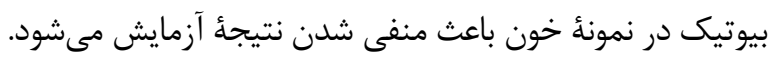




\section{References}

1. Hajia M, Keramat F. Study on the rate of brucellosis relapse and efficiency of different treatment protocols among hospitalized patients. J Mil Med. 2003;5(3):195-9.

2. Hajia M, Soharbi A. Brucellosis: Laboratory Diagnosis, its challenges and prospective. Iran $\mathbf{J}$ Path. 2018;13(2):

3. Pakzad R, Pakzad I, Safiri S, Shirzadi MR, Mohammadpour M, Behroozi A, et al. Spatiotemporal analysis of brucellosis incidence in Iran from 2011 to 2014 using GIS. Int J Infect Dis. 2018;67:129-36. https://doi.org/10.1016/j.ijid. 2017.10.017 PMID:29122689

4. Golshani M, Buozari S. A Review of Brucellosis in Iran: Epidemiology, Risk Factors, Diagnosis, Control, and Prevention. Iran Biomed J. 2017;21(6):349-59. PMID:28766326 PMCID: PMC5572431

5. Hajia M. The Challenges in Diagnosis of Brucellosis Serological Tests and Available Approaches . Iran J Med Microbiol. 2018;12(1):15.

6. WHO. Brucellosis in Humans and animals. World Health Organization, 20 Avenue Appia, 1211 Geneva 27, Switzerland. 2006.

7. Rostami F, Borzoueisileh S, Ebrahimpour S. An overview of brucellosis epidemic in Iran. Crescent Journal of Medical and Biological Sciences. 2016;3(1):35-6. http://www.cjmb.org/pdf.php?id=54

8. Winn W, Allen S, Janda W, Koneman E, Procop G, Schreckenberger P, Woods G. Koneman`s Color Atlas and textbook of Diagnostic Microbiology. Philadelphia: Lippincott Williams and Wilkins; 2006.

9. Moosazadeh M, Abedi G, Kheradmand M, Safiri S, Nikaeen R. Seasonal pattern of brucellosis in Iran: A systematic review and meta-analysis. Iran J Health Sci. 2016;4(1):62-72. http://jhs.mazums.ac.ir/article-1-377-en.html

10. Hajia M, Rahbar M, Keramat F. Epidemiological, clinical, diagnostic and treatment aspects of hospitalized brucellosis patients in Hamadan. Ann Trop Med Public Health. 2009;2(2):42-5.

11. Esmaeili H. Brucellosis in Islamic republic of Iran. Journal of Medical Bacteriology. 2014;3(3-4):4757.

12. Mostafavi E, Asmand M. Trend of brucellosis in Iran from 1991 to 2008. Iran J Epidemiol. 2012;8(1):93-100. http://irje.tums.ac.ir/article-124-en.html
13. Poole PM. A 6-year survey of human brucellosis in a rural area of north-western England and north Wales. Postgrad Med J. 1975;51(597):433-40. http://dx.doi.org/10.1136/pgmj.51.597.433

14. Chamberlin WE. Early history of bovine brucellosis eradication in Australia. Aust Vet J. 1985;62(9):289-92. https://doi.org/10.1111/j.17510813.1985.tb14907.x

15. Eales KM, Norton RE, Ketheesan N. Brucellosis in northern Australia. Am J Trop Med Hyg. 2010;83(4):876-8. https://doi.org/10.4269/ajtmh $.2010 .10-0237$ PMID:20889883 PMCID: PMC2946760

16. Dasjerdi MZ, Nobari RF, Ramezanpour J. Epidemiological features of human brucellosis in central Iran, 2006-2011. Public Health. 2012;126(12):1058-62. https://doi.org/10.1016/ j.puhe.2012.07.001 PMID:22884862

17. Kassiri H, Amani H, Lotfi M. Epidemiological, laboratory, diagnostic and public health aspects of human brucellosis in Western Iran. Asian Pac J Trop Biomed. 2013;3(8):589-94. https://doi.org/10.1016/S2221-1691(13)60121-5

18. Kimman TG, Eric Smit E, Klein MR. EvidenceBased Biosafety: a Review of the Principles and Effectiveness of Microbiological Containment Measures. Clin Microbiol Rev. 2008;21(3):403-25. https://doi.org/10.1128/CMR.00014-08 PMID:18625678 PMCID:PMC2493080

19. Moradi G, Kanani S, Majidpour M, Ghaderi A. Epidemiological status survey of 3880 case of brucellosis in Kurdistan. Iran J Infect Dis Trop Med. 2006;11(33):27-33.

20. Khazaei S, Shojaeian M, Zamani R, Mansori K, Mohammadian-Hafshejani A, Rezaeian-Langroodi R, Ayubi E, Khazaei Z. Epidemiology and risk factors of childhood brucellosis in West of Iran. Int J Pediatr. 2016;4(7):2099-104.

21. Mirnejad R, Jazi FM, Mostafaei S, Sedighi M. Epidemiology of brucellosis in Iran:

A comprehensive systematic review and metaanalysis study. Microb Pathog. 2017;109:239-47. https://doi.org/10.1016/j.micpath.2017.06.005 PMID:28602839

22. Hasanzadeh A, Rahimi I, Shakerian A. Survey of epidemiology brucellosis in Mobarakeh, Esfahan from 2003 to 2010. Bull Env Pharmacol Life Sci. 2013;2(12):87-90.

23. Bokaie S, Sharifi L, Alizadeh H. Epidemiological survey of brucellosis in human and animals in Birjand, east of Iran. J Anim Vet Adv. 2008;7(4):460-3. 
24. Zeinalian Dastjerdi M, Fadaei Nobari R, Ramazanpour J. Epidemiological features of human brucellosis in central Iran, 2006-2011. Public health 2012; 126(12): 1058-1062. 32.

25. Azizi F, Hatami H, Janghorbani M. Epidemiology and control of common diseases in Iran. 4nd ed. Tehran: Khosravi Publishing; 2010.

26. Alavi SM, Mugahi S, Nashibi R, Gharkholu S. Brucellosis risk factors in the southwestern province of Khuzestan, Iran. Int J Enteric Pathog. 2014;2(1):1-4. https://doi.org/10.17795/ijep15610

27. Chegeni AS, Ezatpour B, Saki M, Mokhayeri H, Adavi S, Nasiri E, et al. Seroepidemiology of human brucellosis in nomads in a rural area of Iran. Asian Pac J Trop Dis. 2014;4(4):333-6. https://doi.org/10.1016/S2222-1808(14)60584-3

28. Beheshti S, Rezaian GR, Azad F, Faghiri Z, Taheri F. Seroprevalence of brucellosis and risk factors related to high risk occupational groups in Kazeroon, South of Iran. Int J Occup Environ Med. 2010;1(2):62-8. PMID:23022787

29. Bossi P, Tegnell A, Baka A, Van Loock F, Hendriks J, Werner A, et al. Bichat guidelines for the clinical management of brucellosis and bioterrorism-related brucellosis. Euro Surveill. 2004;9(12):33-4.

https://doi.org/10.2807/esm.09.12.00506-en PMID:29183471

30. Hatami H. Bioterrorism. http://www.hbi.dmr.or.ir(FTP DIR) pub/computerized-books

31. Rita M. Traxler RM, Lehman MW, Bosserman EA, Guerra MA, Smith TL. A Literature Review of Laboratory-Acquired Brucellosis. J Clin Microbiol. 2013;51(9):3055-62. https://doi.org/10.1128/JCM.00135-13 PMID:23824774 PMCID:PMC3754682

32. Bahador A, Mansoori N, Esmaeili D, Sabri RA. Brucellosis: Prevalence and retrospective evaluation of risk factors in western cities of Tehran province, Iran. Afr $\mathbf{J}$ Microbiol Res. 2012;4(3):33-7. https://doi.org/10.5897/JBR12.010

33. Roushan MH, Mohrez M, Gangi SS, Amiri MS, Hajiahmadi M. Epidemiological features and clinical manifestations in 469 adult patients with brucellosis in Babol, Northern Iran. Epidemiol Infect. 2004;132(6):1109-14. $\quad$ https://doi.org/ $\underline{10.1017 / \mathrm{S} 0950268804002833}$

34. Madkour MM, Kasper DL. Brucellosis. In Harrison's principles of internal medicine. Eds:Braunwald E, Fauei AS, Kasper DL, et al. New York: McGraw Hill; 2001. p. 986-9.
35. Amaranth SK, Shinde RS. Review of clinical and laboratory features of human brucellosis. Indian J Med Microbiol, 2007;25(3):188-202. https://doi.org/10.4103/0255-0857.34758

36. Hajia M, Rahbar M. Isolation of Brucella from blood culture of hospitalized brucellosis patients. Iran J Clin Infect Dis. 2006;1(2):5-10.

37. Hajia M, Rahbar M, Taghavi HA. Brucellosis Antibody Level of Hospitalized Patients in Hamadan, Western Iran. Shiraz E Med J. 2007;8(3):1-5.

38. Franco MP, Mulder M, Gilman R, Smits HL. Human Brucellosis. Lancet Infect Dis. 2007;7(12):775-86. https://doi.org/10.1016/S1473-3099(07)70286-4

39. Nielsen K, Smith P, Widdison J, Gall D, Kelly L, Kelly W, et al. Serological relationship between cattle exposed to Brucella abortus, Yersinia enterocolitica O: 9 and Escherichia coli O157: H7. Vet Microbiol. 2004;100(1-2):25-30. https://doi.org/10.1016/j.vetmic.2003.12.010 PMID: 15135510

40. Perry MB, Bundle DR. Lipopolysaccharide antigens and carbohydrates of Brucella. In: Adams LG, editor. Advances in brucellosis research. Austin, Texas: Texas A\&M University Press; 1990. p. 76-88.

41. Zeinali M, Shirzadi MR, Haj rasuliha H. National Guideline for Brucellosis Control. 2nd ed. Tehran: Raz Nahan Publishing; 2012.

42. Zowghi E, Samar G. Interpretation of brucellosis serology tests [in Persian]. Nabz J. 1996;6:30Y34.

43. Zowghi E, Ebadi A. Typing of Brucella strains isolated in Iran. Archive of institute Razi. 1982;33(1):109-14. http://dx.doi.org/10.22092/ari.1982.108881

44. Memish Z, Mah MW, Suliman AM, Shaalan M, Khan Y. Brucella Bacteraemia: Clinical and Laboratory Observations in 160 Patients. J Infect. 2000;40(1):59-63. https://doi.org/10.1053/jinf.1999.0586

45. Christopher S, Umapathy BL, Ravikumar KL. Brucellosis: review on the recent trends in pathogenicity and laboratory diagnosis. J Lab Physicians. 2010;2(2):55-60. https://doi.org /10.4103/0974-2727.72149 PMID:21346896 PMCID:PMC3040083

46. Mantur BG, Amarnath, Shinde RS. Review of Clinical and Laboratory features of human brucellosis. Indian J Med Microbiol 2007;25(3):188-202. $\underline{10.4103 / 0255-0857.34758}$ 


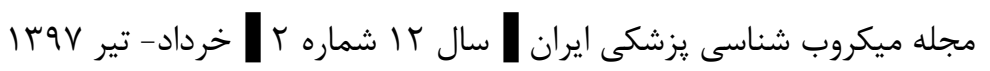

47. Vakili Z, Momen Heravi M, Sharif AR, Masoumi M. Sensitivity and specificity of ELISA test in diagnosis of brucellosis. Kowsar Medical Journal. 2010;15(2):95-8.

48. Amirzargar AA, Hassibi M, Maleknejad P, PiriDougahe H, Jafari S, Bakhsh AS, et al. Comparison of diagnostic methods in hospitalized patients with brucellosis in Iran. Inf Dis Clin Pract. 2009; 17(4):239-42.

https://doi.org/10.1097/IPC.0b013e31818718e8

49. Al-Attas R A, Al-Khalifa M, Al-Qurashi RA, Badway M, Al-Gualy N. Evaluation of PCR, Culture and Serology for the diagnosis of acute human brucellosis. Ann Saudi Med. 2000;20(34):224-8. https://doi.org/10.5144/02564947.2000.224 PMID:17322662

50. Fox KF, Fox A, Nagpal M, Steinberg P, Heroux $\underline{K}$. Identification of Brucella by ribosomal-spacerregion PCR and differentiation of Brucella canis from other Brucella spp. pathogenic for humans by carbohydrate profiles. J Clin Microbiol. 1998;36(11):3217-22. PMID:9774568 PMCID:PMC105304

51. Leal-Klevezas DS, Lopez-Merino A, MartinezSoriano JP. Molecular detection of Brucella spp.: rapid identification of $\mathrm{B}$. abortus biovar I using PCR. Arch Med Res. 1995;26(3):263-7. PMID: 8580678

52. Queipo-Ortuno MI, Morata P, Ocon P, Manchado $\mathrm{P}$, Colmenero JD. Rapid diagnosis of Human brucellosis by peripheral-Blood PCR assay. J Clin Microbiol. 1997;35(11):2927-30. PMID:9350761 PMCID:PMC230089

53. Romero C, Gamazo C, Pardo M, Lopez-Goni I. Specific detection of Brucella DNA by PCR. J Clin Microbiol. 1995;33(3):615-7. PMID:7538508 PMCID:PMC227999

54. Baily GG, Krahn JB Drasar BS, Stoker NG. Detection of Brucella melitensis and Brucella abortus by DNA amplification. J Trop Med Hyg. 1992;95(4):271-5. PMID:1495123

55. Jazi FM, Mirnejad R, Piranfar V, Mozafari NA, Salehi TZ, Khormali M, et al. Real-time PCR and high-resolution melt analysis methods for detection of pathogenic species of Brucella. J Clin Lab Med. 2017;41(6):325-31.

56. Piranfar V, Sharif M, Hashemi M, Vahdati AR, Mirnejad R Detection and discrimination of two Brucella species by multiplex real-time PCR and high-resolution melt analysis curve from human blood and comparison of results using RFLP. Iran J Basic Med Sci. 2015;18(9):909-14. PMID: $\underline{26523223}$ PMCID:PMC4620191
57. Hajia M, Fallah F, Angoti G, Karimi A,Rahbar M, Gachkar L, et al. Comparison of methods for diagnosing Brucellosis. Lab Med. 2013;44(1):2933. https://doi.org/10.1309/LM4J9MWOBIP A6RBN 